\title{
Evolución humana y paz. Una aproximación desde la teoría y la práctica ${ }^{1}$
}

\section{Human evolution and peace. An approach from theory and practice}

\author{
Juan Manuel JimÉnez Arenas \\ Universidad de Granada \\ jumajia@ugr.es
}

Fecha de recepción: 19-1-2018

Fecha de aceptación: 12-3-2018

\section{RESUMEN}

Puede resultar paradójico investigar la paz en la prehistoria, y más concretamente, a partir de los restos de taxones humanos extintos, cuando no tenemos constancia ni del concepto ni, probablemente, la idea de paz. Sin embargo, considerar la paz como una categoría de análisis nos permite visibilizarla en todo tiempo, lugar y por parte de cualquier agente. Por otro lado, esta aportación se inserta dentro de la investigación para la paz, lo que implica que se centra en encontrar ejemplos históricos que permitan transformar la realidad pacíficamente. En este trabajo transitaremos desde la teoría a la práctica partiendo de una definición concreta de paz, la paz imperfecta, entendida como el desarrollo de las capacidades humanas deseables, desde una perspectiva procesual, inacabada, en continuo cambio, cotidiana y paradójica en el sentido de que convive con la violencia. A partir de aquí plantearé cómo la secuenciación del genoma de taxones extintos y la persistencia de trazas de neandertales y denisovanos en nuestro código genético han puesto de manifiesto que, durante la evolución humana, lejos de las lógicas de exterminio que han sido historiográficamente predominantes para explicar la expansión de los humanos anatómicamente modernos, cabe pensar que han primado los flujos y las interrelaciones, a pesar de las diferencias fenotípicas existentes. Como consecuencia, la variabilidad y la diversidad han sido y son fundamentales para la supervivencia de nuestra especie.

PALABRAS CLAVE: paz imperfecta, prehistoria, Paleogenómica, violencia metaestructural, modelos ontológicos.

1 Este trabajo se ha llevado a cabo gracias al apoyo del grupo de investigación HUM-607 de la Junta de Andalucía. Quisiera agradecer a Francisco A. Muñoz Muñoz (in memoriam) quien aún me sirve de inspiración y guía para llevar a cabo la labor como investigador para la paz. A Cándida Martínez López por prestarse a discutir sobre estas temáticas. Y a María Ruiz Hilillo por su encomiable apoyo y revisión del texto. También a los editores de la revista y a los revisores anónimos que han contribuido, sin dudas, a mejorar la versión anterior de este artículo. 


\section{ABSTRACT}

It may appear paradoxical to investigate peace in prehistory, and more specifically, based upon the remains of extinct human taxa, when neither the concept nor, probably, the idea of peace existed. However, considering peace as a category of analysis allows us to visualize it in any time or place and via any agent. Furthermore, this contribution is framed within research for peace, which means that it focuses on finding historical examples that make it possible peacefully to transform reality. The work progresses from theory to practice, beginning with a precise definition of peace, imperfect peace, understood as the development of desirable human capabilities and from a complex perspective (contextual, fluctuating, unfinished, constantly changing, daily and paradoxical -in the sense of coexistence with violence-). This is followed by a consideration of how the sequencing of the genome of extinct taxa and the persistence of traces of Neanderthals and Denisovans in our genetic code have revealed that, during human evolution, contrary to the logics of extermination that have been historiographically predominant, there is reason to believe that interrelationships have prevailed despite the existing phenotypic differences. As a result, it is argued that variability and diversity have been and continue to be crucial to the survival of our species. models.

KEY WORDS: imperfect peace, prehistory, paleogenomic, metastructural violence, ontological

\section{INTRODUCCIÓN}

\subsection{Investigando la y para la paz}

Una de las primeras preguntas que me hice cuando me acerqué, desde la prehistoria, a la investigación para la paz fue: ¿Es posible estudiar la paz en tiempos y por parte de agentes que ni dispondrían de este concepto ni, posiblemente, de tal idea? La respuesta primera devino del nombre que damos a nuestra área de investigación, investigación para la paz (la cursiva es mía). Porque en este caso, la preposición, que marca la relación de dependencia entre los dos sustantivos, indica el sentido (el fin o término, si la aproximación fuese teleológica) al que se encamina una acción. En nuestro caso, la investigación para transformar una realidad que presenta aspectos que resultan sensiblemente mejorables, recurriendo como argumento a nuestro pasado más remoto.

Resulta fácil considerar las paces desde la perspectiva de los valores, de los presupuestos éticos, de las prácticas (Muñoz, 2001). Por el contrario, existen dificultades para su reconocimiento científico. No obstante, la paz debe ser considerada una categoría de análisis: un lugar común, un punto de encuentro, donde se generan novedades conceptuales, teóricas y metodológicas sobre cuestiones que son capitales en humanidades y ciencias sociales ( $v$. g. conflicto, poder, etcétera). El hecho de ser considerada una categoría de análisis convierte a la paz en un resorte que permite interpretar el pasado de manera crítica, en una dinámica básica de la experiencia humana que permite ser reconocida en todo tiempo, en todo lugar y por parte de todas las entidades humanas ${ }^{2}$.

Pero podemos ir más allá, si aplicamos de manera laxa el concepto de hiperrealidad de Baudrillard, si los/as historiadores/as tratamos de establecer un vínculo entre pasado e historia de la misma manera que los/as cartógrafos/as lo plantean entre el territorio y el mapa, en la que el segundo precede al primero en detrimento de este (Baudrillard, 1978: 5). La hiperrealidad no es una interpretación falsa de la realidad, es la constatación de su

2 Entiendo por entidad lo que tiene existencia en sí con independencia del conocimiento que los seres humanos podamos alcanzar sobre ello. 
complejidad, del continuo e inextricable diálogo presente-pasado, en el que se confunde lo real con el modelo (Baudrillard, 1978: 57). Desde una perspectiva aristotélica, el concepto de hiperrealidad puede remitir a la continua amalgama entre historia y poesía, entendida la primera como los sucesos que realmente han acaecido y la segunda como los que pudieron haber acontecido (Aristóteles, Poética IX).

Así, yendo de la historia a la poesía (o viceversa), el pasado, en nuestro caso, el más remoto, se traduce en una hiperrealidad que se convierte en una poderosa herramienta para justificar y legitimar conductas del presente. $Y$ en este sentido, la historia, las ciencias en general, no se alejan mucho de los objetivos de los mitos, y más concretamente de los mitos fundacionales. Esto es, aquellos en los que se establecen características que son fundamentales para la forma que tiene un determinado grupo humano de representarse. El hombre es tal como es hoy día porque ha tenido lugar ab origine de acontecimientos (Eliade, 2000: 85). Los mitos le narran estos acontecimientos y, al hacerlo, le explican cómo y por qué fue constituido de esta manera. Quiénes somos, de dónde venimos o por qué somos como somos, son cuestiones que -entre otras- subyacen cuando estamos investigando sobre nuestros orígenes.

El momento en el que, supuestamente, se fijan esas características es, bajo mi punto de vista, fundamental, crucial. Porque cuanto más antiguas se perciban, más naturales se van a considerar y, por tanto, más justificables y legítimas se estiman. Un ejemplo, el mito de la división sexual del trabajo. Mujeres recolectoras, hombres cazadores, con preeminencia de los segundos y olvidando la importancia de los vegetales en la vida de estos grupos (Berihuete Azorín y Piqué i Huerta, 2006). Sin evidencias que lo sustente de manera empírica y a partir de relatos sobre hombres, generados mayoritariamente por hombres, se busca convertir una pretendida limitación de aquellas a la esfera de lo privado y un presunto protagonismo de estos en lo público en algo naturalizado, que no natural (v. g. Dalhberg, 1975; Sanahuja YII, 2002; Sánchez Romero, 2005; Vilá y Estevez, 2010).

Algo similar ocurre con la violencia. En un exitoso libro de divulgación científica, Los ángeles que llevamos dentro, se plantea que a lo largo de la historia la violencia ha disminuido hasta llegar a sus niveles mínimos en la época contemporánea, y más concretamente a partir del siglo XX (Pinker, 2012). Así las cosas, si percibimos el mundo actual como violento, cuánto más lo habrá sido en el pasado. La cuestión es que este trabajo, escrito por un psicólogo, ha tenido, y prevemos tendrá, un alcance mucho mayor que otros mejor estructurados y fundamentados. Un ejemplo, el reciente artículo de Gómez y colaboradores en el que se sustenta que las muertes por agresiones directas en grupos de recolectorescazadores no era diferente a la de nuestros parientes más cercanos, los grandes simios antropomorfos, los decesos violentos aumentan en las sociedades prestatales para disminuir en las estatales (Gómez y otros, 2016).

La presencia de y la fascinación por la violencia han tenido una influencia capital en el desarrollo de la disciplina de la historia (Guilaine y Zammit, 2002). Sin embargo, desde la perspectiva de una particular visión de la paz, la paz imperfecta, se plantea que a lo largo de la historia de la humanidad, los conflictos se han gestionado y transformado mayoritariamente de manera pacífica (v. g. Muñoz, 2001; Jiménez Arenas, 2011; Jiménez Arenas y Muñoz Muñoz, 2013). O al menos de forma que hoy podría considerarse pacífica. Por ello, se plantea una reinterpretación de la historia en clave pacífica. Si nuestra máxima preocupación es la paz, sitúese en el centro de nuestra investigación.

Sin embargo, si evaluamos la producción de la mayoría de los centros internacionales de investigación para la paz, se constata un sesgo hacia el estudio de la violencia ${ }^{3}$,

3 Ver, por ejemplo, los informes que generan instituciones tan importantes como el SIPRI (2017), el PRIO 
presuponiendo que su conocimiento nos conducirá a un mundo más pacífico. Por tanto, un primer apunte sería, si vis pacem para pacem; así transitemos desde enfoques violentológicos hacia pazológicos. Este giro no pretende inventar algo nuevo, sino plantear desde la mirada de la investigación para la paz, interpretaciones alternativas sobre nuestro pasado, que se centren en los tiempos, espacios y agentes de paz.

\subsection{Prehistoria para la paz. Un estado de la cuestión}

No han sido muchos los trabajos vinculados a la prehistoria que se han tejido siguiendo los caminos descritos arriba. No obstante, es relevante tenerlos en cuenta y discernir sus aportaciones. La primera referencia que plantea la cooperación como un factor clave en la evolución de las especies, incluidas las humanas, fue El apoyo mutuo del pensador de origen ruso Piotr A. Kropotkin (2005). Desde una perspectiva libertaria, propone que el mutualismo ha sido un comportamiento predominante y alternativo a la ortodoxia darwinista que plantea, como motor evolutivo, la lucha por la existencia y la supervivencia de los más aptos. A pesar de sus sugerentes y documentadas propuestas, las ideas de Kropotkin no tuvieron demasiado éxito. De hecho, coquetear con este tipo de aproximaciones podía traer consecuencias muy negativas, como las sufridas por el humanista Ashley Montagú quien prologó la edición editada en Boston por Extending Horizons Books, Porter Sargent Publishers de 1955 y fue purgado por comunista durante la represión macartista. Además, Montagú destacó por la denuncia de las falacias escondidas tras el concepto "raza" ( $v$. $g$. Montagú, 1972), siendo uno de los ponentes de la Declaración de la Unesco titulada The Race Question (1950).

Aunque previamente otros autores habían propuesto la presencia de la cooperación en los albores de la salida de Homo fuera de África (Lordkipanidze y otros, 2005), serán autoras/es como Jean Jacques Hublin (2009) y Spikins, Rutherford y Needham (2010), los/ as que establezcan un vínculo expreso entre compasión y prehistoria. El primer trabajo es una reflexión aparecida en la prestigiosa revista Proceedings of the National Academy of Sciences a propósito de la publicación de un cráneo de un individuo infantil del yacimiento de la Sima de los Huesos (Atapuerca, Burgos) con una fusión temprana de sus huesos lo que le provocaría una anormal maduración cerebral y tortícolis crónica (Gracia y otros, 2009). El segundo de los artículos parte de la prehistoria de las emociones puesto que consideran a la compasión una experiencia "socio-moral" que debió evolucionar a partir de la cooperación de nuestros ancestros en un medio más conflictivo, si lo comparamos con nuestros parientes vivos más cercanos, como es la sabana (Spikins y otros, 2010). Además, los humanos presentamos diferencias significativas en cuestiones como la empatía y la compasión si nos comparamos con aquellos.

Ahora bien, se trata de aportaciones que se limitan a una parte, eso sí importante, de lo que denominamos paz: la compasión. Esta se define según el Diccionario de la Real Academia Española de la Lengua como "sentimiento de pena, de ternura y de identificación ante los males de alguien" y en inglés, según el diccionario Collins, como "a feeling of pity, sympathy, and understanding for someone who is suffering". Ambas definiciones incluyen un término parecido understanding-identificación-. Empero, uno de los grandes problemas de la paz es precisamente ese, su identificación para su entendimiento. Ya Galtung (1990) delimitó su famoso triángulo en el que se ponía de manifiesto que la mayor parte de las formas que adoptan las violencias -y las paces- permanecen, a la manera de un iceberg, habitualmente ocultas y silenciosas.

Un año después, en 2011, publiqué un capítulo de libro que lleva inserto expresamente el concepto de paz. El título pretendió ser elocuente: Pax Homínida. Una aproximación 
imperfecta a la evolución humana. Aparte de hacer un repaso a las evidencias de cuidados, de solidaridad, altruismo y filantropía que han jalonado la evolución de nuestro linaje, se atisban otras, menos obvias, aunque igualmente persuasivas. Por ejemplo, las interrelaciones (poblacionales, aunque no exclusivamente sexuales ${ }^{4}$ ) que se produjeron entre neandertales y humanos anatómicamente modernos, lo que supone una propuesta alternativa a la visión a la historia concebida como "lógicas de exterminios" que ha sido historiográficamente predominante (Jiménez Arenas, 2011). La conclusión fue que los comportamientos que hoy podemos considerar pacíficos-cooperativos, solidarios, altruistas y filantrópicos- han sido clave para la supervivencia de nuestros antepasados y los son para nuestra propia supervivencia y deberían ser considerados de la misma manera que se hace con el bipedismo o la encefalización.

En 2015 se editó en un volumen dedicado a la arqueología de la infancia, un capítulo en el que abordé la relación entre infancia, complejidad y cooperación desde una perspectiva evolutiva (Jiménez Arenas, 2015). De las conclusiones a las que arribé destacaré tres. En primer lugar, que la aparición de la infancia supone que individuos inmaduros no tengan que depender de manera tan directa de las mujeres para su alimentación y otros miembros del grupo se pueden hacer cargo de los cuidados. En segundo lugar, que el período de crecimiento de los neandertales y los humanos anatómicamente modernos es similar y, por tanto, el período de aprendizaje-enseñanza más intenso es semejante. El tercero, que la interrelación entre un gran cerebro, un tiempo de maduración lento y la mayor colaboración de individuos a la hora de la socialización provocan una mayor complejidad socio-cultural.

Muy recientemente, Spikins y colaboradores (2017) han publicado un trabajo en el que se realiza una revisión del comportamiento simbólico de los neandertales estableciendo múltiples semejanzas con los humanos anatómicamente modernos. En este estudio se pone de manifiesto la capacidad de abstracción de aquel taxón así como su alta sociabilidad. Trabajos como este suponen una "humanización" de los neandertales, lo cual entraría dentro de un concepto amplio de paz. En este sentido, es relevante poner de manifiesto que una de las características de la violencia es la cosificación del "otro", lo que conlleva considerar que no comparten las mismas capacidades que "nosotros".

De lo anteriormente expuesto se deduce que tanto el concepto de paz como el modelo ontológico del que partamos serán fundamentales para el desarrollo de nuestra práctica investigadora.

4 La cuestión de la sexualidad en la prehistoria ha sido ampliamente debatida. En su influyente artículo "The origin of man", O. C. Lovejoy (1981) planteaba que ya desde A. afarensis, una especie muy dimórfica (v. g. Jiménez Arenas, 2006), la forma de relación predominante entre machos y hembras fue la monogamia. Sin embargo, estudios posteriores ponen de manifiesto que existe una relación entre las diferencias de tamaño de machos y hembras y el sistema de apareamiento en primates no humanos (v. g. Plavcan, 2000), siendo los muy dimórficos tendentes a vivir en harenes o en grupos en los que se establece una fuerte jerarquía reproductiva y los que no presentan esas diferencias tan acusadas propensos a la monogamia. En el caso de Homo, la población de Dmanisi, considerada "habilina" en algunos trabajos (Agustí y Lordkipanidze, 2011; Jiménez-Arenas y otros, 2011; Lordkipanidze y otros, 2007) y Homo erectus en otros (Lordkipanidze y otros, 2013) se ha caracterizado como muy dimórfica. Empero, con Homo erectus s. I., y más concretamente a partir de la población de la Sima de los Huesos (Arsuaga y otros, 1997), las diferencias en la masa corporal estimada disminuyen significativamente, lo que implicaría, en principio, un cambio en el sistema de apareamiento. Por tanto, se puede inferir que la competencia reproductiva sería significativamente menor a partir de ese momento. Aún así, es difícil de interpretar cómo eran esas relaciones. No obstante, es posible continuar especulando con que un mayor equilibrio en el número de machos y hembras provocaría mayores posibilidades de apareamiento para todos los miembros del grupo y, por tanto, menores tensiones [ver Gray (2013) para una revisión de la sexualidad humana desde una perspectiva evolutiva]. Por otra parte, la ausencia de báculo en los humanos se pone en relación con la escasa o nula existencia de "competencia poscopulatoria" entre los machos (Brindle y Opie, 2016). 


\section{PAZ, ¿QUÉ PAZ?}

\subsection{Una breve historia de la evolución del concepto de paz}

Aunque resulta resbaladizo establecer la aparición de cada una de ellos, la paz ha transitado desde una práctica, pasando por idea y culminando en concepto. Este último ha variado a lo largo de las décadas que van desde el final de la II Guerra Mundial a nuestros días (Martínez Guzmán, 2001). El primero que nos encontramos es la paz negativa, entendida como la ausencia de guerra o más genéricamente como la ausencia de violencia directa. Está muy marcada por agendas, aún hoy día vigentes, en las que el armamentismo y el desarme detentaron, y detentan, un papel fundamental. Este concepto de paz resulta excesivamente limitante si no se atiende a otras instancias de la violencia y la paz.

Años después surge la paz positiva, que se gesta a finales de los sesenta al calor de un concepto tremendamente exitoso, la violencia estructural, incubada por el matemático y sociólogo noruego Johan Galtung (1969). Este autor capital para la investigación para la paz, detectó formas invisibles e indirectas de violencia que son causadas mediante la explotación que provoca marginalización y segmentación, que están presentes en las estructuras de los sistemas político-económicos -específicamente en el liberal-capitalistay que refuerza el carácter sistémico de la violencia. Lo último es fundamental porque remarca las interrelaciones entre las diferentes instancias de la violencia. Para Galtung es fundamental, si pretendemos construir un mundo más justo y equitativo, reconocer estas formas de violencia, mucho más sutiles y difíciles de detectar y que producen empobrecimiento, inequidades e injusticias. De ahí la expresión frecuentemente vinculada a la paz positiva: paz con justicia social. Ahora bien, dos de los principales problemas que presenta el fértil binomio violencia estructural-paz positiva son: 1) que es imprescindible cambiar de manera significativa las estructuras para que se perciban avances en materia de paz y 2) que, dado que la paz se opone a la violencia, es necesario acabar con toda la violencia del mundo para poder considerar a este como pacífico, lo que la convierte en utópica, en un paraíso en la Tierra.

Con la venida del nuevo milenio, se comenzó a repensar la paz desde presupuestos alternativos a los tradicionales provenientes de la modernidad. La postmodernidad $y$, con posterioridad, la transmodernidad están contribuyendo a alumbrar nuevas conceptualizaciones de la paz que encuentran alternativas menos estructurantes, más abiertas y menos maximalistas. Entre ellas destacan la paz transracional de Wolfgang Dietrich $(2013,2014)$ y la paz imperfecta de Francisco A. Muñoz Muñoz (2001). Sólo unas líneas sobre la primera para centrarme en la segunda por ser el marco conceptual en el que me muevo y en el que se desarrolla esta contribución.

La paz transracional alude a la coexistencia de múltiples racionalidades que, de una $\mathrm{u}$ otra forma, remiten a una idea o imagen, y no necesariamente un concepto, de la paz. Las paz transracional presenta cuatro categorías de paces: las paces energéticas (que buscan la armonía, la unificación de dualidades mediante intercambios), las paces morales (que polarizan pares que se refieren a un fin último), las paces modernas (que aluden a lo que se percibe, a la racionalidad y lo sensorial y que implican responsabilidad) y las paces postmodernas (que remiten a ideas como desconfianza, desilusión e incredulidad, pero también pluralidad). Se trata de una paz relacional, compleja y sistémica que trata de evitar la dicotomización y en la que la experiencia es clave porque nos hace. Para ello la paz transracional recurre al método elicitivo ideado por John Paul Lederach (2005) para la transformación de conflictos y a la transdisciplinariedad aplicada por Adam Curle (1999).

Así pues, los conceptos de paz acaban condicionando las agendas de investigación que, por otra parte, no sólo son cada vez más extensas sino también más interrelacionadas, 
lo que nos obliga a reconocer la complejidad como espacio donde necesariamente enmarcar su abordaje (Muñoz Muñoz y Molina Rueda, 2010). Efectivamente, los diversos escenarios de la paz, los actores y actrices implicados/as en ella, sus proyectos, sus circunstancias, tiempos hacen que tengamos que integrar dimensiones cuantitativas y cualitativas cambiantes. ¿Cómo afrontar, pues, esta complejidad que por sí sola no sólo crea incertidumbre sino que, también, podría llegar a paralizarnos? La propuesta, de la cual participo, es la paz imperfecta, presentada y primeramente desarrollada por Francisco A. Muñoz Muñoz (Muñoz, 2001).

\subsection{La paz imperfecta}

La paz transracional y la paz imperfecta convergen en muchos puntos. Partiré de tres: 1) se trata de conceptualizaciones autónomas de paz, esto es, que no dependen directamente de la violencia, 2) son complejas y 3) incluyen el denominado giro epistemológico (Martínez Guzmán, 2001), esto es, si la paz es nuestra preocupación y nuestro anhelo, situemos la paz en el centro de nuestra práctica investigadora.

Desde la perspectiva de la paz imperfecta planteamos una matriz compuesta por cinco ejes: una teoría general de los conflictos, pensar desde un paz imperfecta; deconstruir la violencia; discernir las mediaciones e interacciones sistémicas entre conflictos, paz y violencia; y el empoderamiento pacifista. Se trata de "lugares comunes" de la investigación para la paz a lo largo de sus años de existencia (Muñoz Muñoz, 2001; Muñoz Muñoz y Molina Rueda, 2010). La novedad reside en la ampliación del giro epistemológico al ámbito de lo ontológico, lo que supone una demanda "radical" para la actualización de los presupuestos sobre los que pensamos la investigación de y para la paz.

\subsubsection{Los conflictos}

A partir de los trabajos de Muñoz y colaboradores/as (v. g. Muñoz y López Martínez, 2000; Muñoz, 2001; Muñoz Muñoz y Molina Rueda, 2010; Jiménez Arenas y Muñoz Muñoz, 2013) se plantea que los conflictos no son ni sinónimo ni antesala de la violencia, sino el resultado de las diferencias en las percepciones, objetivos y desarrollo de capacidades entre distintas entidades humanas, y puede entenderse como "un proceso interactivo que se da en un contexto determinado. Es una construcción social diferenciada de la violencia" (Fisas, 1998: 185) El conflicto, entendido desde un prisma positivo, es fuente de creatividad y de oportunidades, y abre la posibilidad al cambio y a la transformación. El conflicto forma parte del proceso de interacción social en el que los intereses de los individuos y grupos se entrelazan, se regulan, transforman o resuelven en ocasiones, convirtiéndose en una parte esencial del complejo desarrollo de socialización que experimenta toda entidad humana. Entender el conflicto desde esta perspectiva supone pues formas de reconocimiento mutuo (asimilar la alteridad y la diversidad humana) y de comprensión de las percepciones del otro (la inexistencia de una única verdad, de una única visión de la realidad, etcétera).

Por tanto, se considera el conflicto como primera condición de nuestra capacidad para optar y que, desde los inicios de nuestra historia, la mayor parte de aquellos se han gestionado pacíficamente. Esto supone que los humanos no somos ni pacíficos ni violentos por naturaleza (Martínez Fernández y Jiménez Arenas, 2003).

\subsubsection{La paz imperfecta}

Se entiende como tal aquellas situaciones en las que se consigue el máximo de desarrollo de las capacidades humanas de acuerdo con las condiciones sociales y personales de partida (Muñoz, 2001). Se denomina imperfecta porque está en permanente construcción, es cotidiana y ubicua, perfectible, inacabada y convive con los conflictos y, aunque 
pueda parecer contradictorio, con la violencia. Pero más allá de su cualidad de imperfecta, el carácter sistémico de la paz hace que se entrelacen sus múltiples instancias. Entender la paz desde este punto de vista nos permite romper con las concepciones anteriores en las que la paz aparece como total, infalible, utópico, terminado, lejano, no alcanzable en lo inmediato. En segundo lugar, una paz imperfecta contribuye a reconocer las prácticas pacíficas allá donde ocurren y nos descubre estos hitos como soportes de una paz mayor, más amplia. Y en tercer lugar una paz imperfecta nos ayuda a planificar unos futuros conflictivos y siempre incompletos.

La imperfección nos acerca a lo más humano de nosotros mismos, ya que en nosotros conviven emociones y cultura, deseos y voluntades, egoísmo y filantropía, aspectos positivos y negativos, aciertos y errores. También, permite que nos reconozcamos como actores y actrices siempre inmersos/as en procesos dinámicos e inconclusos, ligados a la incertidumbre y la fragilidad.

La imperfección asimismo nos remite a una de las ideas que defiendo con mayor ahínco desde hace años: todas las entidades humanas tienen capacidades para la gestión pacífica de los conflictos. De tal forma que resulta significativo y a la vez enriquecedor reconocer las paces imperfectas especialmente en aquellas entidades humanas que podemos reconocer como nuestros particulares leviatanes, rompiendo las dinámicas basadas en las lógicas del enemigo por las de adversario. Por tanto, una de las tareas principales de todos las/os investigadoras/es para la paz debe ser rescatar las realidades de la paz, reconocer todas las acciones en las cuales ella está presente, todas las predisposiciones, actitudes y acciones -individuales, subjetivas, sociales y estructurales- que en nuestros actos de hablar o expresar, pensar, sentir y actuar estén relacionados con la paz.

\subsubsection{Visibilización y crítica de las violencias}

Sin la existencia de la violencia ni hablaríamos ni investigaríamos la paz. Y aquella se puede definir como conductas o situaciones que, de forma deliberada, aprendida o imitada, provocan o amenazan con hacer daño o sometimiento grave [físico, verbal o psicológico (emotivo-cognitivo)] a las entidades humanas (desde individuos a la especie) y/o a los entornos y contextos en los que establecen sus interrelaciones para el desarrollo de sus capacidades, impidiéndolas o limitándolas en el presente y/o en el futuro. Puede producirse a través de acciones, pero también se nutre de silencios e inacciones. Dicho de otra manera, "todo aquello que, siendo evitable, no promueve, obstaculiza o incluso impide el desarrollo de las potencialidades [capacidades] deseables de los seres humanos" (Sánchez Cazorla, 1997: 15).

Lamentablemente, podemos encontrar innumerables formas y escenarios de violencia. Y las principales formas que adoptan las violencias son la directa, la estructural, la cultural, la simbólica y la metaestructural. Ahora bien, aunque esta separación resulta operativa, los ejercicios de la violencia incluyen la interacción entre los diferentes tipos de violencia. No obstante, pasaré a la descripción de cada uno de ellos.

La violencia directa se refiere a la que se concreta en comportamientos y acciones intencionados que provocan daños físicos, psíquicos, emocionales, sentimentales, ambientales, etcétera. En ella se produce una identificación de víctimas y victimarios y es la más visible y fácilmente reconocible de entre los tipos de violencias. Una cuestión fundamental es separarla de la agresividad, entendida como toda pulsión tendente al mantenimiento y/o transmisión de la vida, cuya base es fisiológica y que permite la supervivencia en un medio externo que se revela como conflictivo (Simón, 1991: 3).

La violencia estructural es, como ya se ha comentado anteriormente, un concepto enunciado por Johan Galtung, un tipo de violencia indirecta provocada por cada uno de los sistemas económicos y políticos, especialmente el liberal-capitalista, sintetizada en la injus- 
ticia social, la pobreza, las inequidades y relacionada con otras circunstancias que hacen que muchas de las capacidades de la población no se hagan realidad. Otra característica de la violencia estructural es la interconexión entre las diferentes instancias de la violencia. Por eso, de un tiempo a esta parte, consideramos denominarla sistémica (Muñoz Muñoz y Jiménez Arenas, 2015) y así enfatizar esta característica.

La violencia metaestructual se presenta en el presente trabajo y se refiere a aquella que transciende los sistemas y estructuras políticas y económicas de tal manera que se puede rastrear en múltiples contextos y circunstancias. Una de sus principales fuentes de justificación y legitimación es la naturalización de la desigualdad. Por eso, resulta especialmente interesante su vínculo con la prehistoria en general, y con la evolución humana en particular, porque aspectos como la violencia patriarcal o racial, se valen de discursos biologizados para naturalizar tales inequidades, lo que conecta este tipo de violencia con la cultural.

Esta última, la cultural, también es debida a Galtung y alude a las formas de legitimación y justificación de las violencia directa, estructural y metaestructural a través de la esfera simbólica de nuestra existencia: lenguajes, artes, ciencias, medios de comunicación, religiones, sistemas políticos, etcétera (Galtung, 1990). Una característica fundamental es que se percibe como correcta.

La violencia simbólica se reserva para los casos en los que los dominadores imponen un orden gnoseológico: el sentido inmediato del mundo ( $y$, en particular, del mundo social) en términos de jerarquía y desigualdad (Bourdieu, 1991). Es producida y apropiada por las clases dominantes, representando la ortodoxia, la oficialidad. Contribuye a que las clases dominadas acepten su rol, delimitado por las dominadoras, lo que la conecta con el concepto de hegemonía gramsciano (Gramsci, 1991) e implica una complicidad tácita entre ambos grupos. La violencia simbólica ayuda a naturalizar (interiorizar) y reproducir ese mundo social inequitativo.

\subsubsection{Las mediaciones}

La mediación es un concepto que permite relacionar elementos distintos a través de agentes que cumplen la función de interponerse entre varias circunstancias. Considerándola desde una perspectiva filosófica-epistémica, la mediación es una reflexión racional en la que se incorporan más ideas y un proceso dialógico a través del cual se pueden encontrar las relaciones. Su capacidad interpretativa y de materialización está fuera de toda duda y es importante abordarla tanto en su aspecto más abstracto, en la articulación de las ideas, como en su concreción, en la interpretación de las realidades y las acciones prácticas.

La mediación tiene una dimensión topológica, de escenario, de lugar, y otra dialógica como recurso epistémico que puede ser reconocido en determinadas relaciones y acciones. Aquella, tal como apuntábamos antes, nos facilita encontrar entes y prácticas humanas que enlazan los conflictos con la paz, estimulándola. En la regulación pacífica de los conflictos la negociación es una de las formas más reconocidas y dentro de ellas la mediación es el mecanismo utilizado en muchas ocasiones para favorecer y acercar las posiciones iniciales de los actores. Por tanto, la mediación es una de las formas por excelencia de prevenir y regular conflictos.

\subsubsection{Empoderamiento pacifista}

Resulta fundamental reformular el poder desde una perspectiva pacifista, olvidando concepciones relacionadas con la imposición, control, subordinación, coerción, etcétera y, sobre todo, con su carácter externo, lo que invita a tener que tomarlo (las más de las veces por medios violentos). Ahora bien, el poder puede ser también entendido desde otros puntos de vista. Así, Foucault (1979 y 1980) lo plantea como una continua negociación en 
el que el poder se cede y se ejerce provocando continuos cambios en las correlaciones de fuerza. Esta propuesta, aunque tremendamente fértil e inspiradora, resulta insuficiente para girar el concepto de poder desde una perspectiva pacifista. Sin negar la existencia de las formas de ejercer el poder antes expuestas, desde la investigación para la paz proponemos la coexistencia de un poder creativo, positivo, basado en la creación de redes, en la cooperación y en el convencimiento de que las experiencias, escenarios, tiempos y actores/ actrices de paz, contribuyen a la transformación de la realidad (Boulding, 1993). Además, defendemos que todas las entidades humanas tienen poder, considerado como la capacidad para transformar la realidad, y lo ejercen. Para ello partimos de esos poderes capilares relacionales, reticulares y que están presentes en todas las entidades humanas, en sus habitus (Muñoz Muñoz y Bolaños Carmona, 2011).

A partir del giro en el concepto de poder, se define el empoderamiento pacifista en un doble sentido, el primero, como la toma de conciencia de las capacidades que tenemos los seres humanos para la transformación pacífica de los conflictos, y el segundo, como todos aquellos procesos en que la paz, la transformación pacífica de los conflictos, la satisfacción de necesidades o el desarrollo de capacidades ocupan el mayor espacio personal, público y político posible. Pensamos que el empoderamiento pacifista es un concepto central en la construcción de la paz. Ambos sentidos son complementarios y sinérgicos: la toma de conciencia de las capacidades precede y es necesaria para la acción pacífica en todos sus niveles (micro, meso, macro) convirtiéndose en nexo entre la teoría y la práctica. Lo es porque da recursos de transformación individual-social-colectiva $y$, asimismo, porque nos obliga a indagar sobre las realidades de la paz, lo que nos retrotrae directamente a la filosofía para hacer las paces (Martínez Guzmán, 2001) o la paz imperfecta (Muñoz, 2001). Representa, al mismo tiempo, una categoría académica de las disciplinas que se dedican al estudio de la paz; y una realidad propositiva y ejemplarizante. El empoderamiento pacifista pretende rescatar la praxis de la paz, conseguir que las acciones de paz tengan el mayor espacio personal, público y político a pesar de su convivencia con los conflictos y la violencia. En el caso que nos ocupa, a partir de la prehistoria.

\section{MODELOS ONTOLÓGICOS, SESGOS E IDENTIDAD}

Los modelos ontológicos remiten a cómo concebimos al ser humano en abstracto. Si seguimos al fundador de la fenomenología trascendental, Ernest Husserl, sería la parte de la filosofía que se preocupa por el estudio de las esencias formales, esto es, aquellas esencias que convienen a todas las demás esencias (Ferrater Mora, 2004), de tal manera que se convierten en una potente forma de legitimación y justificación de determinados discursos sobre la realidad. Por tanto, el concepto ontológico del cual participamos, tendrá una influencia capital en la forma en la cual construimos la realidad, incluida nuestra identidad. Además, las prácticas contribuyen a su afianzamiento.

Se pueden definir dos grandes modelos ontológicos:

Uno, negativo del ser humano epitomizado en la frase de Thomas Hobbes "El ser humano es un lobo para el ser humano", y otro, positivo que se resume en el mito del buen salvaje de Jean Jacques Rousseau.

Para el primero, los humanos son esencialmente violentos. Y si nuestra esencia es violenta sólo puede ser superada mediante el concurso de la cultura. El contrato social deviene de la necesidad de superar ese estado natural de la humanidad que es la lucha de "todos contra todos". Entronca con la tradición judeocristiana, con la expulsión del paraíso y ha tenido, y tiene aún mucho éxito (liberalismo, marxismo, darwinismo, darwinismo social, sociobiología...) Para el segundo, los humanos son esencialmente pacíficos. Sólo la aparición de la propiedad privada generó egoísmo y en definitiva, violencia. Rousseau 
influye en pensadoras/es posteriores (Kropotkin, Ashley Montagu, teóricas feministas, investigadoras/es para la paz).

Ahora bien, desde la perspectiva que se viene proponiendo en el concepto de paz imperfecta, los seres humanos no somos ni esencialmente violentos, ni esencialmente pacíficos; somos primariamente conflictivos. Por tanto, urge un modelo ontológico imperfecto.

Tanto la paz como la violencia son construcciones culturales, históricas y por tanto, contingentes. Desde una perspectiva compleja que permite el reconocimiento de la convivencia de aspectos aparentemente antagónicos, en los seres humanos conviven, como ya he expresado anteriormente, comportamientos cooperativos y egoístas, altruistas y codiciosos, pacíficos y violentos.

¿Qué relación se puede establecer entre modelos ontológicos y la prehistoria? Que esta se convierte en el tiempo y el espacio inmejorable para plantear cuitas que tienen que ver con las presuntas esencias de los seres humanos; en particular aquellas que responden a la lógica de los mitos fundacionales. De tal forma que se trata de "esencializar" aspectos tan importantes para parte de la humanidad actual como: la preeminencia de los seres humanos dentro de la naturaleza; el predominio de unos grupos (especies) humanos sobre otros; la superioridad de unos complejos culturales respecto a otros; la división sexual del trabajo; la naturaleza violenta o pacífica de los seres humanos, etcétera. Esto remarca el carácter de hiperrealidad de nuestra práctica puesto que, como afirma Almudena Hernando, "el contenido de nuestros discursos de conocimiento está determinado por los intereses, conflictos, preocupaciones y sensibilidad general de cada época" (Hernando, 1999: 19), que son la base para la generación y reproducción de los hábitus (Bourdieu, 1977) y que se convierten en los esquemas generativos a partir de los cuales un grupo determinado interpreta la realidad y actúa en ella (Hernando, 1997).

Ahora bien, además de figurar como la metonimia y la metáfora (Olson, 1994), las disciplinas históricas pueden funcionar como el sinécdoque, aspirando a designar el todo a partir de una parte. Esto implica un nivel de selección importante. De tal manera que, parafraseando a D. L. Clarke, la prehistoria no es inocente (Clarke, 1973). Por tanto, cuáles sean esos procesos de selección, conscientes e/o inconscientes, van a condicionar las narraciones, los sesgos, los prejuicios y los discursos, las justificaciones y legitimaciones de un status quo concreto. No obstante, hay que reconocer que también ha servido, y sirve, para la transformación social. Así, las identidades -actuales- van a jugar un papel fundamental, puesto que comparto con Felipe Criado Boado "la importancia que a menudo la prehistoria y las etapas remotas de la historia (que sólo mediante la arqueología pueden ser conocidas) adquieren para fundar la identidad" (Criado Boado 2001: 36), esto es, comportamientos que son fundamentales para la forma que tiene una parte de la humanidad de representarse. En el caso de la supuesta naturaleza humana propongo que no sea ni violenta ni pacífica sino conflictiva.

Tradicionalmente se enfatizado el carácter excluyente de las identidades, de su conformación en base a la alteridad (Barth, 1969), lo que resalta la diferencia y, en no pocas ocasiones, la desigualdad que se legitima y justifica. Ahora bien, no es menos cierto que las identidades tienen también un marcado carácter inclusivo. Esto dota a las identidades de un carácter complejo y dialógico establecido entre los aspectos exo- y endo- de las mismas. Es más, desde el giro epistemológico y ontológico vinculado a la paz imperfecta, se valora el reconocimiento y realce de la diversidad, tender a la equidad. Una equidad que no podrá serla sin las perspectivas de género, edad y población.

Para ello es fundamental entender que las entidades humanas somos el resultado de una compleja combinación de características identitarias. Esto no significa que no existan características más o menos fijas, sino que en las identidades conviven lo más pasajero con 
lo más permanente. Las identidades son históricas y contingentes. Más aún, se modelan y moldean durante la vida de los seres humanos a la manera de un caleidoscopio en el que los diferentes aspectos van intersectando de forma distinta dando lugar a figuras diferentes. Por tanto, las entidades humanas somos el resultado de una compleja combinación de características identitarias -móviles, inestables, heterogéneas, presentes, imperfectas(Garcés Montoya, 2005) que conviven bajo un discurso ficticio de unicidad (Vila, 2002).

Recapitulando, la relación entre el pasado y el presente es fundamental para entender la función identitaria de las ciencias del pasado, y en particular de la Prehistoria. La interpretación en Prehistoria está, bajo mi punto de vista, preñada por ese carácter de hiperrealidad, de "cante de ida y vuelta", que entrevera hechos, evidencias y prejuicios. Y en todos ellos, los modelos ontológicos y epistemológicos juegan roles capitales.

\section{INTERACCIONES Y FLUJOS}

Los trabajos sobre prehistoria de la compasión (Hublin, 2009; Spikins y otros, 2010) y sobre la paz homínida (Jiménez Arenas, 2011) han enfatizado la presencia de la cooperación, la solidaridad, el altruismo y la filantropía como comportamientos presentes en los homínidos desde hace, al menos, 1,8 millones de años. Sin embargo, desde la perspectiva de la paz imperfecta cabe incorporar, a la manera de Spikins y colaboradoras (2017), otro tipo de experiencias a la caracterización de las conductas de los representantes del género Homo. En este caso me centraré en las interacciones y flujos entre diferentes poblaciones prehistóricas consideradas especies diferentes.

\subsection{La Historia como lógica de exterminios}

La Historia, como disciplina, se ha construido mayoritariamente en torno a la violencia, considerándose uno de sus principales motores. Así, Hegel plantea en su filosofía de la historia que las luchas, el sufrimiento, se convierten en constantes históricas de tal forma que las metas finales sólo serán alcanzadas tras un largo camino por este valle de lágrimas de la historia, "el calvario del Espíritu absoluto" (Hegel, 1971: 473). Esta concepción es tomada por Marx quien propone que "La violencia es la comadrona de toda sociedad vieja que lleva en sus entrañas otra nueva. Es, por sí misma, una potencia económica" (Marx, 1986: 639). Esta frase ha inspirado la imagen que tenemos de la historia y en particular de las revoluciones, de las cuales se visibilizan, casi exclusivamente, sus aspectos violentos. Como muestra tomaré las imágenes icónicas de las revoluciones francesa -toma de la Bastilla- y rusa -asalto al Palacio de Invierno-.

Se trata, de cualquier modo, de una historia pesimista (si acaso el futuro devendrá diferente) que se va configurando en torno a lógicas de exterminios físico y cultural. Si bien la primera puede resultar más obvia, la segunda presenta también una larga tradición que se remonta a finales del siglo XIX cuando McGee (1896) estableció que existía una transmisión y ajuste entre los grupos humanos superiores y los inferiores que acababa por diluir, hasta la desaparición, las costumbres de los segundos que, en este proceso, transitaban desde la barbarie a la civilización. Llevado hasta las últimas consecuencias se alcanzarían genocidios culturales, como se puede extraer fácilmente del concepto epistemicidio de Ramón Grosfoguel (2013). Esta idea, no obstante, viene siendo cuestionada desde la década de los 30 del siglo pasado por autores como Redfield, Linton y Herskovits (1936) quienes propusieron que el contacto entre diferentes poblaciones provoca cambios en los sistemas culturales (entendidos en el más amplio sentido de la expresión) de ambos.

Los humanos anatómicamente modernos procedemos de África, aunque la nueva datación de Jebel Irhoud podría situar su origen lejos de la región que tradicionalmente se había considerado la cuna de la humanidad (Hublin y otros, 2017). Nuestros orígenes 
son lejanos en el tiempo y también en el espacio. Así, muy recientemente se ha propuesto que la primera salida fuera de África se produjera hace 180000 años (Hershkovitz y otros, 2018), aunque de momento no tenemos evidencias de que se adentraran más allá del corredor sirio-palestino. Conforme esas poblaciones fueron avanzando se fueron encontrando con los habitantes del continente euroasiático, humanos cuyos fenotipos eran bien diferentes. Los africanos oscuros de piel, estilizados, con cráneos más altos, más anchos en la parte superior, con menor prognatismo facial y mentón, se encontraron con las poblaciones neandertales, claros de piel, muchos de ellos/as pelirrojos/as, de menor estatura y más corpulentos, con cráneos más bajos y robustos, con arcos superciliares muy marcados, narices anchas y prominentes caras. De los denisovanos, un taxón que sólo se ha encontrado en Asia, apenas conocemos dos molares y una falange (Sawyer y otros, 2015), y por tanto su apariencia física sigue enterrada.

\subsection{Una Historia alternativa. Flujos poblacionales}

¿Qué puede aportar la evolución humana al debate sobre supuestos exterminios? Creo que mucho. Hasta hace poco tiempo era arrolladoramente mayoritaria la visión que proponía que allá por donde los humanos modernos iban avanzando, desparecían las especies humanas (y no humanas) precedentes (v. g. Stringer y Gamble, 1996; Hortolá y Martínez-Navarro, 2013). Interpretaciones que se sitúan en el extremo del paradigma de la competencia de Charles Darwin en el que la "lucha por la existencia" se torna, parafraseando a Alfred Tennyson, "roja en diente y garra".

Todo parecía confluir en pos de la sustentación de la denominada "hipótesis de la sustitución". Incluido el ADN mitocondrial (ADNmt) (Serre y otros, 2004) que presentaba diferencias muy significativas entre los humanos anatómicamente modernos y los neandertales, lo que justificaba la propuesta de aislamiento reproductivo entre ambos taxones y extinción de estos debido a la superioridad tecnológica y la mayor capacidad de explotación de los entornos por parte de aquellos. No obstante, incluso en los momentos de mayor fuerza de la "hipótesis de la sustitución", se alzaron voces disidentes que proponían que el flujo genético fue constante durante toda la evolución humana (Wolpoff, 1999). El espaldarazo definitivo a las propuestas que se basaban en la interacción vino de la mano de la secuenciación del genoma neandertal (Green y otros, 2010). A partir de este trabajo la comunidad científica internacional se vio obligada a reconocer la existencia de flujo genético entre ambas poblaciones.

Esto tiene una enorme trascendencia puesto que el concepto biológico de especie, que se debe a Buffon (1801: 160 y ss.) y es el que late y se considera hegemónico, dicta que dos organismos pertenecen a la misma especie siempre y cuando sean capaces de tener descendencia y que esta sea fértil ${ }^{5}$. Dicho de otra manera, y siguiendo el criterio antes expuesto, dos o más individuos se clasifican como especies diferentes cuando se produce un aislamiento reproductivo definitivo entre ellos. Neandertales y humanos anatómicamente modernos tuvieron descendencia fértil, aunque no toda la humanidad actual porta el legado

\footnotetext{
5 No obstante, el debate sobre qué es una especie dista de ser cerrado. Aunque en este trabajo se ha optado por el denominado "concepto biológico", existen otros muchos. En paleontología el más usado es el morfológico, que permite clasificar en función de la forma (Weller, 1949). No obstante, este criterio fue criticado, casi inmediatamente, por Simpson puesto que "the degree of morphological difference within what everyone, morphologist, geneticist, or other, calls a single species is frequently greater than that between what all call separate, related species. It is also quite impractical to obtain a valid, over-all measure of total morphological difference between two organisms" (Simpson, 1951: 287). A esto hemos de añadir las problemáticas para (1) diferenciar entre caracteres homólogos u homoplásicos y (2) evaluar los factores implicados en la variabilidad intraespecífica.
} 
de aquellos. Los africanos subsaharianos no, ¿por qué? Porque sólo una pequeña parte de la población de humanos anatómicamente modernos salió de África. Sapiens extrañados que se diseminaron por el mundo encontrándose con moradores locales. Las poblaciones humanas actuales americanas, asiáticas, europeas, norteafricanas y oceánicas presentan un porcentaje de genoma neandertal que oscila entre un 1,5 y 4 \% (Green y otros, 2010). Ahora bien, esta cantidad es mayor cuanto más nos aproximamos al momento de las interacciones, como se desprende de la secuenciación del ADN de uno de los primeros humanos anatómicamente modernos del continente europeo recuperado en el yacimiento de Peştera cu Oase (Rumanía). El individuo denominado Oase 1, presenta una antigüedad de entre 37000 y 42000 años y entre un 6 y $9 \%$ de genoma neandertal (Fu y otros, 2015).

Así pues, esta nueva realidad tiene consecuencias interesantes desde la perspectiva de la investigación para la paz.

La primera es que los únicos humanos anatómicamente de los que no se tiene constancia de flujo genético con taxones conocidos pertenecen a poblaciones africanas subsaharianas. La segunda es que los encuentros fueron múltiples (entre 100000 y 70000 en Asia Central y entre 47000 y 65000 en el resto del continente euroasiático, incluyendo el corredor sirio-palestino) (Sankararaman y otros, 2012; Kuhlwilm y otros, 2016). Las restantes poblaciones somos una mezcla caleidoscópica de diferentes "especies", fragmentos intersectados y cambiantes, retales en palabras de Svante Pääbo, director de Genética Evolutiva del Instituto Max Planck de Leipzig (Alemania) (Tancredi Barone, 2014). La tercera es que esos encuentros, esas interrelaciones, esos flujos genéticos continúan configurando a una parte de los seres humanos actuales. Así, los denisovanos nos legaron una mayor capacidad para vivir en altitudes elevadas (Huerta-Sánchez y otros, 2014) y los neandertales aspectos relacionados con la catabolización de las grasas, color de la piel, mayor cantidad de queratina y enfermedades del presente: depresión, obesidad, trastornos cardiovasculares, adicciones (Simonti y otros, 2016). Es oportuno aclarar que el legado de estos proporcionó, originalmente, ventajas adaptativas a poblaciones que vivieron en condiciones diferentes a las de su origen (África) que, sin embargo, la interacción con factores socio-ambientales actuales han convertido en deletéreas. En palabras de las/os autoras/es del trabajo anterior: "It is possible that some Neandertal alleles provided a benefit in early $\mathrm{AMH}$ populations as they moved out of Africa, but have become detrimental in modern Western environments" (Simonti y otros, 2016: 741).

Lo interesante es la producción de la siguiente paradoja: a pesar de que la investigación más avanzada ha puesto de manifiesto la anteriormente comentada mezcla de poblaciones, sin embargo, seguimos pensando en términos de aislamiento y poniendo todas las cortapisas habidas y por haber a la inclusión de los neandertales y los humanos anatómicamente modernos en una única especie, Homo sapiens, estableciendo la distinción en el nivel de subespecie: Homo sapiens sapiens, Homo sapiens neanderthalensis ${ }^{6}$.

Así las cosas, emerge una pregunta, ¿por qué si la genética apunta a un flujo entre poblaciones, en algunos casos muy diferentes anatómica y morfológicamente, persiste el paradigma de la sustitución y del aislamiento reproductivo? Obedece a una forma de entender el mundo y de considerar las relaciones sociales y políticas que se vale de la

6 Siendo consciente de que la denominación más habitual es Homo neanderthalensis-Homo sapiens, la combinación de diferencias fenotípicas entre ambos taxones y la confirmación de que entre ambos tuvieron descendencia fértil me lleva a recuperar que la distinción taxonómica debería situarse en el nivel subespecie, entendida como poblaciones que teniendo un origen común, en un momento dado se aíslan geográfica y reproductivamente lo que provoca una diferenciación morfológica, aunque al volver a ser simpátricas producen descendentes que mantienen la capacidad para reproducirse (Mayr, 1982). 
violencia metaestructural para justificar y legitimar un discurso sobre la realidad en el que la diferencia se convierte en desigualdad. A esto hemos de añadir la concepción de la propia ciencia que actúa como sistema de validación para determinadas formas de justificación y legitimación de un orden concreto del que destacaré dos: el racismo y el colonialismo.

El primero implica la consideración de los "otros" como sujetos aislados, inferiores y con una "esencialidad" marcadamente diferente respecto a la de los que encarnan la superioridad (los "nosotros") (para profundizar en esta discusión ver Gould, 1997). Evidentemente, este tipo de prácticas buscan, como ya he planteado anteriormente, convertir la diferencia en desigualdad. Ahora bien, las formas que adopta este "nuevo racismo científico" son mucho más sutiles y elaboradas que las dominantes durante el siglo XIX y primera mitad del XX (por ejemplo, la craneometría, la frenología y la eugenesia), presentando una característica interesante, la traslación, en la que se mueve el debate a otro tiempo en el que los protagonistas son otros actores. Aún así, comparte con las viejas formas la consideración inferior de lo diferente.

Por otra parte, los "otros", encarnados en los neandertales, y presentados como poblaciones con menor desarrollo social, cultural y tecnológico, sirven para remarcar la capacidad de innovación y progreso de los humanos anatómicamente modernos. De esa forma, por ejemplo, a los primeros se les ha negado o minimizado capacidades similares a las de nuestro taxón. Así, se rechazó que los neandertales explotaran recursos tales como los marinos y los animales de pequeña talla (lagomorfos y aves). No obstante, recientes investigaciones permiten sustentar que sí lo hicieron (Cortés-Sánchez y otros, 2011; Fa y otros, 2013). Otro caballo de batalla relevante ha sido las capacidades simbólicas (ver Spikins y otros, 2017). Cualquier atisbo de actividad que pudiera implicar un desarrollo importante del pensamiento abstracto, se cuestionaba o, en todo caso, se consideraba una burda copia a partir del modelo "sapiens". Empero, las evidencias vuelven a reconocer la cercanía conductual entre ambos taxones. Neandertales y humanos anatómicamente modernos comparten la misma variante del gen FOXP2 que está implicado en las capacidades neurológicas para la producción y entendimiento del lenguaje (Krause y otros, 2007). Además, son múltiples las evidencias de uso de pigmentos y adornos -conchas y dientes perforados para ser usados como colgantes- que se vinculan con el ámbito de lo simbólico (Caron y otros, 2011). Asimismo, son destacables los conocimientos de los neandertales en cuanto a medicina natural, lo que implica que los cuidados eran muy intensos (Hrdy y otros, 2012). Por último, cabe subrayar sus prácticas funerarias (Rendu y otros, 2014) que podrían implicar, teóricamente, la negación de la finitud de la vida humana y la creencia en un más allá. Ahora bien, a pesar de estas evidencias, los neandertales siguen siendo representados y percibidos como seres inferiores; las ciencias del pasado al servicio de la legitimación de la desigualdad (Jiménez Arenas, 2002).

El segundo aspecto de este orden del mundo, el colonialismo, deviene de pensar que los humanos anatómicamente modernos, portadores de un desarrollo tecnológico mayor que las poblaciones "autóctonas", se superponen a las formas culturales preexistentes. Esta percepción recuerda sobremanera a las formas de actuar de las potencias coloniales ya desde el siglo XVI y que tan bien refleja McGee en el concepto de aculturación antes aludido.

Así las cosas, los fenotipos, los cuerpos neandertales, no sólo son materiales, se cargan de significados, de estereotipos que provocaron su separación y repulsión. A este rechazo ha contribuido la imagen que se ha transmitido de los neandertales. Aunque los últimos años han supuesto un cambio significativo de la imagen de los neandertales, tradicionalmente se les ha representado gráficamente como casi-simios/apenas-humanos: prognatos, peludos y encorvados, aunque reconocibles. Vinculado a esto, una idea muy foucaultiana: 
la subyugación de los cuerpos y el control de la población (Foucault, 1978); o dicho de otra manera, cómo deben de ser los cuerpos humanos, qué cuerpos son normales. Como plantea Rosemary A. Joyce (2005) los cuerpos son construcciones simultáneas de estatus social, género/sexo, raza, etnia, edad y clase. En nuestro caso, podríamos cambiar raza por población, concepto que puede incluir también diferentes taxones porque las diferencias anatómicas y morfológicas, en definitiva, corporales, han conllevado planteamientos esencialistas en los que las diferencias han tornado en desigualdades.

Así, la evolución humana participa, como elemento justificador y legitimador, mediante procesos de naturalización, de un orden sociopolítico concreto. En este caso, la desigualdad a partir de la apariencia física. Esto entronca con la que hemos denominado violencia metaestructural puesto que contribuye a perpetuar tal modelo mediante el recurso a la naturalización -cuanto más antiguo y más persistente sea una característica, un comportamiento, una institución, etcétera más natural se considera- y por tanto, menos posibilidad de cambio existe. En este caso a través de narraciones sobre nuestro pasado que tratan de darle un barniz de verdad, o verosimilitud, a través del componente científico. Un sapienscentrismo que contribuye a que no desaparezca la creencia de superioridad biológica, cultural y moral de unos grupos humanos respecto a otros y limita el reconocimiento, en términos de igual, de la diversidad fenotípica y cultural que ha acompañado al menos, los 200000 últimos años de la historia de la humanidad.

Ahora bien, desde una perspectiva transmoderna, no me quedaré en una crítica de la violencia. La endogamia y el aislamiento son generalmente negativos, y, por tanto, los flujos, las interrelaciones contribuyeron a que los neandertales estén todavía presentes. Lejos de contribuir a su desaparición, hemos ayudado a su continuidad. Las diferencias fenotípicas, evidentes, entre neandertales y humanos anatómicamente modernos no han sido suficientes como para convertirse en barreras, en fronteras invisibles que contribuyen, de forma sutil, a perpetuar discursos racistas sobre la realidad.

La diversidad biológica y cultural es clave para nuestro presente y puede serlo para nuestro futuro. La gran variabilidad de nuestra especie (que, recordemos, incluye a las poblaciones neandertales y denisovanas) ha ayudado a que nos hayamos convertido en la única especie ecuménica de primates. Además, una menor variabilidad puede implicar una reducción de la viabilidad poblacional, sobre todo cuando estas son pequeñas ( $v$. g. Conner y White, 1999). Un ejemplo actual de esta tendencia la tenemos en un taxón relativamente cercano, evolutivamente hablando a nosotros, los gorilas de montaña (Gorilla beringei). Esta población ha visto reducido su número dramáticamente en los últimos 20000 años lo que conlleva una disminución de su variabilidad genética y un aumento de las mutaciones deletéreas (Xue y otros, 2015). Este escenario implica para los gorilas de montaña una menor capacidad para hacer frente a los cambios ambientales y a la evolución de los patógenos. Por tanto, la variabilidad, la diversidad han sido, son y serán fundamentales para la supervivencia de los humanos.

Lejos de las lógicas de exterminio que han prevalecido en las narraciones sobre evolución humana, la Paleogenómica está poniendo de manifiesto cómo los flujos y las interacciones han contribuido a modelar lo que somos hoy, posiblemente la especie más compleja que habita la Tierra.

\section{BIBLIOGRAFÍA}

AGUSTÍ, J. y LORDKIPANIDZE, D. (2011): "How 'African' was the early human dispersal out of Africa?", Quaternary Science Reviews, 30, 1338-1342.

ARSUAGA, J. L.; CARRETERO, J. M.,; LORENZO, C.; GRACIA, A.; MARTÍNEZ, I.; BERMÚDEZ DE CASTRO, J. M. y CARBONELL, E. (1997): "Size variation in Middle Pleistocene humans", Nature, 277, 1086-1088. 
AUTORES VARIOS (1950): The race question, Nueva York, UNESCO, http://unesdoc. unesco.org/images/0012/001282/128291eo.pdf [Consulta: 12-12-2017].

BARTH, F. (1969): Ethnic groups and boundaries. The social organization of culture difference, Oslo, Universitetsforlaget.

BAUDRILLARD, J. (1978): Cultura y simulacro, Barcelona, Kairós.

BERIHUETE AZORÍN, M. y PIQUÉ I HUERTA, R. (2006): "Semillas, frutas, leña, madera: El consumo de plantas entre las sociedades cazadoras-recolectoras", Revista AtlánticaMediterránea de Prehistoria y Arqueología Social, 8, 35-51.

BOULDING, K. (1993): Las tres caras del poder, Barcelona, Paidós.

BOURDIEU, P. (1977): Outline of a theory of practice, Cambridge, Cambrigde University Press.

BOURDIEU, P. (1991): Language and symbolic power, Oxford, Polity Press.

BRINDLE, M. y OPIE, C. (2016): "Postcopulatory sexual selection influences baculum evolution in primates and carnivores", Proceedings of the Royal Society B, 283, 0161736.

BUFFON (1801): Histoire Naturelle, Paris, Hacquart, https://ia801403.us.archive.org/24/ items/histoirenatur04buff/histoirenatur04buff.pdf. [Consulta: 08-03-2018].

CARON, F.; D'ERRICO, F.; DEL MORAL, P.; SANTOS, F. y ZILHÃO, J. (2011): "The reality of Neandertal symbolic behavior at the Grotte du Renne, Arcy-sur-Cure, France", PLoS ONE, 6, e21545.

CLARKE, D. L. (1973): "Archaeology: The loss of innocence", Antiquity, 47, 6-18.

CONNER, M. M. y WHITE, G. C. (1999): "Effects of individual heterogenety in estimating the persistente of small populations", Natural Resources Modeling, 12, 109-127.

CORTÉS-SÁNCHEZ, M.; MORALES-MUÑIZ, A.; SIMÓN-VALLEJO, M. D.; LOZANOFRANCISCO, M. C.; VERA-PELÁEZ, J. L.; FINLAYSON, C.; RODRÍGUEZ-VIDAL, J.; DELGADO-HUERTAS, A.; JIMÉNEZ-ESPEJO, F. J.; MARTÍNEZ-RUIZ, F.; MARTÍNEZAGUIRRE, M. A.; PASCUAL-GRANGED, A. J.; BERGADÀ-ZAPATA, M. M.; GIBAJABAO, J. F.; RIQUELME-CANTAL, J. A.; LÓPEZ-SÁEZ, J. A.; RODRIGO-GÁMIZ, M.; SAKAI, S.; SUGISAKI, S.; FINLAYSON, G.; FA, D. A. y BICHO, N. F. (2011): "Earliest known use of marine resources by Neanderthals", PLoS One, 6, e24026.

CRIADO BOADO, F. (2001): "La memoria y su huella. Sobre arqueología, patrimonio e identidad", Claves de la Razón Práctica, 115, 36-43.

CURLE, A. (1999): To tame the Hydra: Undermining the culture of violence, Charlbury, Jon Carpenter Publishing.

DALHBERG, F. (1975): Woman the gatherer, London, Yale University Press.

DIETRICH, W. (2013): Elicitive conflict transformation and the transrational shift in peace politics, London, Palgrave Macmillan.

(2014): "A brief introduction to transrational peace research and elicitive conflict transformation", Journal of Conflictology, 5, 48-57.

ELIADE, M. (2000): Aspectos del mito, Paidós, Madrid.

FA, J. E.; STEWART J. R.; LLOVERAS. L. y VARGAS, J. M. (2013): "Rabbits and hominin survival in Iberia", Journal of Human Evolution, 64, 233-241.

FERRATER MORA, F. (2001): "Husserl, Edmund", en Ferrater Mora, F., Diccionario de Filosofía, vol. 2, Barcelona, Círculo de Lectores, 1712-1719, (nueva edición revisada, aumentada y actualizada por J. M. Terricabas, bajo la supervisión de P. Cohn Ferrater Mora).

FISAS, V. (1998): Cultura de paz y gestión de conflictos, Barcelona, Icaria.

FOUCAULT, M. (1978): Historia de la sexualidad. La voluntad del saber, vol. 1, Madrid, Siglo XXI. 
(1979): Microfísica del poder, Madrid, Las Ediciones de la Piqueta.

(1996): La verdad y las formas jurídicas, Barcelona, Gedisa.

$\overline{F U}$, Q.; HAJDINJAK, M.; MOLDOVAN, O. T.; CONSTANTIN, S.; MALLICK, S.; SKOGLUND, P.; PATTERSON, N.; ROHLAND, N.; LAZARIDIS, I.; NICKEL, B.; VIOLA, B.; PRÜFER, K.; MEYER, M.; KELSO, J.; REICH, D. y PÄÄBO, S. (2015): "An early modern human from Romania with a recent Neanderthal ancestor", Nature, 524, 216-219.

GALTUNG, J. (1969): "Violence, peace, and peace research", Journal of Peace Research, 6, 167-191.

(1990): "Cultural Violence", Journal of Peace Research, 27, 291-305.

GARCÉS MONTOYA, A. P. (2005): Nos-otros los jóvenes: polisemias de las culturas y los territorios musicales en Medellín, Medellín, Sello Editorial Universidad de Medellín.

GOULD, S. J. (1997): La falsa medida del hombre, Barcelona, Crítica.

GRAMSCI, A. (1991): Escritos políticos (1917-1933), México, Siglo XXI.

GRAY, P. B. (2013): "Evolution and human sexuality", American Journal of Physical Anthropology, 57, 94-118.

GROSFOGEL, R. (2013): "Racismo/sexismo espistémico, universidades occidentalizadas y los cuatro genocidios/epistemicidios del largo siglo XVI", Tabula Rasa, 19, 31-58.

GUILAINE, J. y ZAMMIT, J. (2002): El camino de la guerra. La violencia en la prehistoria, Barcelona, Ariel.

GÓMEZ, J. M.; VERDÚ, M.; GONZÁlEZ-MEGÍA, A.; y MÉNDEZ, M. (2016): “The phylogenetic roots of human lethal violence", Nature, 538, 233-237.

GRACIA, A.; ARSUAGA, J. L.; MARTÍNEZ, I.; LORENZO, C.; CARRETERO, J. M.; BERMÚDEZ DE CASTRO, J. M. y CARBONELL, E. (2009): "Craniosynostosis in a Middle Pleistocene human: Cranium 14 from the Sima de los Huesos, Atapuerca, Spain", PNAS, 106, 6573-6578.

GREEN, R. E.; KRAUSE, J.; BRIGGS, A. W.; MARICIC, T.; STENZEL, U.; KIRCHER, M.; PATTERSON, N.; LI, H.; ZHAI, W.; FRITZ, M. H. Y.; HANSEN, N. F.; DURAND, E. Y.; MALASPINAS, A. S.; JENSEN, J. D.; MARQUES-BONET, T.; ALKAN, C.; PRUFER, K.; MEYER, M.; BURBANO, H. A.; GOOD, J. M.; SCHULTZ, R.; AXIMU-PETRI, A.; BUTTHOF, A.; HOBER, B.; HOFFNER, B.; SIEGEMUND, M.; WEIHMANN, A.; NUSBAUM, C.; LANDER, E. S.; RUSS, C.; NOVOD, N. N.; AFFOURTIT, J.; EGHOLM, M.; VERNA, C.; RUDAN, P.; BRAJKOVIC, D.; KUCAN, Z.; GUSIC, I.; DORONICHEV, V. B.; GOLOVANOVA, L. V.; LALUEZA-FOX, C.; DE LA RASILLA, M.; FORTEA, J.; ROSAS, A.; SCHMITZ, R. W.; JOHNSON, P. L. F.; EICHLER, E. E.; FALUSH, D.; BIRNEY, E.; MULLIKIN, J. C.; SLATKIN, M.; NIELSEN, R.; KELSO, J.; LACHMANN, M.; REICH, D. y PÄÄBO, S. (2010): "A draft sequence of the Neandertal genome", Science, 328, 710-722.

HARDY, K.; BUCKLEY, S.; COLLINS, M. J.; ESTALRRICH,A.;BROTHWELL, D.; COPELAND, L.; GARCÍA-TABERNERO, A.; GARCÍA-VARGAS, S.; DE LARASILLA, M.; LALUEZAFOX, C.; HUGUET, R.; BASTIR, M.; SANTAMARÍA, M. D.; MADELLA, M.; WILSON, J.; CORTÉS, A. F. y ROSAS, A. (2012): "Neanderthal medics? Evidence for food, cooking, and medicinal plants entrapped in dental calculus", Naturwissenschaften, 99, 617-626.

HERSHKOVITZ, I.; WEBER, G. W.; QUAM, R.; DUVAL, M.; GRÜN, R.; KINSLEY, L.; AYALON, A.; BAR-MATTHEWS, M.; VALLADAS, H.; MERCIER, N.; ARSUAGA, J. L.; MARTINÓN-TORRES, M.; BERMÚDEZ DE CASTRO, J. M.; FORNAI, C.; MARTÍN-FRANCÉS, L.; SARIG, R.; MAY, H.; KRENN, V. A.; SLON, V.; RODRÍGUEZ, L.; GARCÍA, R.; LORENZO, C.; CARRETERO, J. M.; FRUMKIN, A.; SHAHACKGROSS, R.; BAR-YOSEF MAYER, D. E.; CUI, Y.; WU, X.; PELED, N.; GROMAN- 
YAROSLAVSKI, I.; WEISSBROD, L.; YESHURUN, R.; TSATSKIN, A.; ZAIDNER, Y. y WEINSTEIN-EVRON, M. (2018): "The earliest modern humans outside of Africa", Science, 359, 456-459.

HERNANDO, A. (1997): "Mitos, metáforas y miedos: sobre la prehistoria y sus habitantes", Complutum, 8, 247-260.

(1999): "Percepción de la realidad y Prehistoria. Relación entre la construcción de la identidad y la complejidad socio-económica en los grupos humanos", Trabajos de Prehistoria, 56, 19-35.

HEGEL, E. (1971): Fenomenología del Espíritu, México, Fondo de Cultura Económica.

HORTOLÁ, P. y MARTÍNEZ-NAVARRO, B. (2013): “The Quaternary megafaunal extinction and the fate of Neanderthals: An integrative working hipótesis", Quaternary International, 295, 69-72.

HUBLIN, J. J. (2009): "The Prehistory of compassion", PNAS, 106, 6429-6430.

HUBLIN, J. J.; BEN-NCER, A.; BAILEY, S. E.; FREIDLINE, S. E.; NEUBAUER, S.; SKINNER, M.; BERGMANN, I.; LE CABEC, A.; BENAZZI, S.; HARVATI, K. y GUNZ, P. (2017): "New fossils from Jebel Irhoud, Morocco and the pan-African origin of Homo sapiens", Nature, 546, 289-292.

HUERTA-SÁNCHEZ, E.; JIN, X.; BIANBA, A. Z.; BENJAMIN, P. M.; VINCKENBOSCH, N.; LIANG, Y.; YI, X.; HE MING, Z.; SOMEL, M.; PEIXIANG, N.; WANG, B.; OU, X.; HUASANG LUOSANG, J.; CUO, Z. X. P.; LI, K.; GAO, G.; YIN, Y.; WANG, W.; ZHANG, X.; XU, X.; YANG, H.; LI, Y.; WANG, J.; WANG, J. y NIELSEN, R. (2014): "Altitude adaptation in Tibetans caused by introgression of Denisova-like DNA", Nature, 512, 194-197.

JIMÉNEZ ARENAS, J. M. (2002): "La función social de las ciencias del pasado. Stephen Jay Gould in memorian", Dynamis, 22, 535-549.

(2006): Estudio de la variación craneométrica en homínidos y sus inferencias paleobiológicas y filogenéticas, Granada, Editorial de la Universidad de Granada.

(2011): "Pax Homínida. Una aproximación imperfecta a la evolución humana", en MUÑOZ MUÑOZ, F.A. y BOLAÑOS CARMONA, M.J. (eds.), Los habitus de la Paz. Teorías y prácticas de la Paz, Granada, Editorial de la Universidad de Granada, 65-94. (2015): "Complexity, cooperation and chidhood: An evolutionary perspective, en Sánchez Romero, M.; Alarcón García, E. y Jiménez Aranda, G. (eds.), Children, spaces and identity, Oxford, Oxbow, 26-39.

JIMÉNEZ ARENAS, J. M. y MUÑOZ MUÑOZ, F. A. (eds.) (2013): La paz, partera de la Historia, Granada, Editorial de la Universidad de Granada.

JIMÉNEZ-ARENAS, J. M.; PALMQVIST, P. y PÉREZ-CLAROS, J. A. (2011): "A probabilistic approach to the craniometric variability of the genus Homo and inferences on the taxonomic affinities of the first human population dispersing out of Africa", Quarternary International, 243, 219-230.

JOYCE, R. A. (2005): "Archaeology of the body", Annual Review of Anthropology, 34, 139158.

KRAUSE, J.; LALUEZA-FOX, C.; ORLANDO, L.; ENARD, W.; GREEN, R. E.; BURBANO, H. A.; HUBLIN, J. J.; HÄNNI, C.; FORTEA, J.; DE LA RASILLA, M.; BERTRANPETIT, J.; ROSAS, A. y PÄÄBO, S. (2007): "The derived FOXP2 variant of modern humans was shared with Neandertals", Current Biology, 17, 1908-1912.

KROPOTKIN, P. (2005): Mutual aid: A factor of Evolution, Manchester, Extending Horizons Books (original publicado en 1902 en Nueva York por la editorial McLure Phillips \& Co.).

KUHLWILM, M.; GRONAU, I.; HUBISZ, M. J.; DE FILIPPO, C.; PRADO-MARTINEZ, J.; KIRCHER, M.; FU, Q.; BURBANO, H. A.; LALUEZA-FOX, C.; DE LA RASILLA, M.; 
ROSAS, A; RUDAN, P.; BRAJKOVIC, D.; KUCAN, Ž.; GUŠIC, I.; MARQUES-BONET, T.; ANDRÉS, A. M.; VIOLA, B.; PÄÄBO, S.; MEYER, M.; SIEPEL, A. y CASTELLANO, S. (2016): "Ancient gene flow from early modern humans into Eastern Neanderthals", Nature, 530, 429-433.

LEDERACH, J. P. (2005): The moral imagination: The art and soul of building peace, Nueva York, Oxford University Press.

LORDKIPANIDZE, D.; VEKUA, A.; FERRING, R.; RIGHTMIRE, P. G.; AGUSTI, J.; KILADZE, G.; MOUSKHELISHVILI, A.; NIORADZE, M.; PONCE DE LEÓN, M. S.; TAPPEN, M. y ZOLLIKOFER, C. P. E. (2005): "The earliest toothless hominin skull", Nature, 434, 717-718.

LORDKIPANIDZE, D.; JASHASHVILI, T.; VEKUA, A.; DE LEON, M. S. P.; ZOLLIKOFER, C. P. E.; RIGHTMIRE, G. P.; PONTZER, H.; FERRING, R.; OMS, O.; TAPPEN, M.; BUKHSIANIDZE, M.; AGUSTI, J.; KAHLKE, R.; KILADZE, G.; MARTINEZ-NAVARRO, B.; MOUSKHELISHVILI, A.; NIORADZE, M. y ROOK, L. (2007): "Postcranial evidence from early Homo from Dmanisi, Georgia", Nature, 449, 305-310.

LORDKIPANIDZE, D.; PONCE DE LEÓN, M. S.; MARGVELASHVILI, A.; RAK, Y.; RIGHTMIRE, G. P.; VEKUA, A. y ZOLLIKOFER, C. P. E. (2013): "A complete skull from Dmanisi, Georgia, and the evolutionary biology of early Homo", Science, 342, 326-331.

LOVEJOY, C. O. (1981): "The origin of man", Science, 211, 341-350.

MARX, K. (1986): El capital: Crítica de la economía política, vol. III, México, Fondo de Cultura Económica.

MARTÍNEZ FERNÁNDEZ, G. y JIMÉNEZARENAS, J. M. (2003): “Los humanos prehistóricos ni pacíficos ni violentos por naturaleza sino todo lo contrario", en Muñoz, F. A. y Pérez Beltrán, C. (eds.), Experiencias de Paz en el Mediterráneo, Granada, Editorial de la Universidad de Granada.

MARTÍNEZ GUZMÁN, V. (2001): Filosofía para hacer las paces, Barcelona, Icaria.

MAYR, E. (1982): "Of what use are subspecies?, The Auk, 99, 593-595.

MCGEE, W. J. (1898): "Piratical acculturation", American Anthropologist, 11, 243-249.

MONTAGÚ, A. (1972): Statement on Race, New York, Oxford University Press.

MUÑOZ, F. A. (ed.) (2001): La paz imperfecta, Granada, Editorial de la Universidad de Granada.

MUÑOZ, F. A. y LÓPEZ MARTÍNEZ, M. (eds.) (2000): Historia de la paz: tiempos, espacios $y$ actores, Granada, Editorial de la Universidad de Granada.

MUÑOZ MUÑOZ, F.A. y BOLAÑOS CARMONA, M.J. (eds.) (2011): Los habitus de la Paz. Teorías y prácticas de la Paz, Granada, Editorial de la Universidad de Granada.

MUÑOZ MUÑOZ, F. A. y MOLINA RUEDA, B. (2010): "Una cultura de paz compleja y conflictiva. la búsqueda de equilibrios dinámicos", Revista de paz y conflictos, 3, 4461.

MUÑOZ MUÑOZ, F. A. y JIMÉNEZ ARENAS, J. M. (2015): "Histoire et recherche pour la paix. Expériences autour de la Méditerranée", Cahiers de la Méditerranée, 91, 165178.

OLSON, D. R. (1994): The World on paper. The conceptual and congnitive implication of writing and reading, Cambridge, Cambrigde University Press.

PINKER, S. (2012): Los ángeles que llevamos dentro. El declive de la violencia y sus implicaciones, Barcelona, Paidós.

PLAVCAN, J. M. (2000): "Inferring social behavior from sexual dimorphism in the fossil record", Journal of Human Evolution, 39, 327-344.

RENDU, W.; BEAUVAL, C.; CREVECOEUR, I.; BAYLE, P.; BALZEAU, A.; BISMUTH, T.; 
BOURGUIGNON, L.; DELFOUR, G.; FAIVRE, J. P.; LACRAMPE-CUYAUBÈRE, F.; TAVORMINA, C.; TODISCO, D.; TURQ, A. y MAUREILLE, B. (2013): "Evidence supporting an intentional Neandertal burial at La Chapelle-aux-Saints", PNAS, 111, 81-86.

REDFIELD, R.; LINTON, R. y HERSKOVITS, M. J. (1936): "Memorandum for the study of acculturation", American Anthropologist, 38, 149-152.

SANAHUJA YLL, E. (2002): Cuerpos sexuados, objetos y prehistoria, Madrid, Cátedra.

SÁNCHEZ CAZORLA, J. A. (1997): "Ciencia y tecnología para la paz", en Rodríguez Alcázar, F. J.; Medina Doménech, R. M. y Sánchez Cazorla, J. A. (eds.), Ciencia, tecnología y sociedad: contribuciones para una cultura de la paz, Granada, Editorial de la Universidad de Granada, 15-47.

SÁNCHEZ ROMERO, M. (ed.) (2005): Arqueología y Género, Granada, Editorial de Universidad de Granada.

SANKARARAMAN, S.; PATTERSON, N.; LI, H.; PÄÄBO, S. y REICH, D. (2012): "The date of interbreeding between Neandertals and modern humans", PLoS Genetics, 8, e1002947.

SAWYER, S.; RENAUD, G.; VIOLA, B.; HUBLIN, J. J.; GANSAUGE, M. T.; SHUNKOV, M. V.; DEREVIANKO, A. P.; PRÜFER, K.; KELSO, J. y PÄÄBO, S. (2015): "Nuclear and mitochondrial DNA sequences from two Denisovan individuals", PNAS, 112, 15696-15700.

SERRE, D.; LANGANEY, A.; CHECH, M.; TESCHLER-NICOLA, M.; PAUNOVIC, M.; MENNECIER, P.; HOFREITER, M.; POSSNERT, G. y PÄÄBO, S. (2004): "No evidence of neandertal mtDNA contribution to Early Modern Humans", PLoS Biology, 2(3), e57.

SIMÓN, P. (1991): La Noviolencia, Emmanuel Mounier, Madrid.

SIMONTI, C. N.; VERNOT, B.; BASTARACHE, L.; BOTTINGER, E.; CARRELL, D. S.; CHISHOLM, R. L.; CROSSLIN, D. R.; HEBBRING, S. J.; JARVIK, G. P.; KULLO, I. J.; LI, R.; PATHAK, J.; RITCHIE, M. D.; RODEN, D. M.; VERMA, S. S.; TROMP, G.; PRATO, J. D.; BUSH, W. S.; AKEY, J. M.; DENNY, J. C. y CAPRA, J. A. (2016): "The phenotypic legacy of admixture between modern humans and Neandertals", Science, 351, 737-741.

SIMPSON, G. G. (1951): “The species concept”, Evolution, 5, 285-298.

SIPRI (2017): SIPRI Yearbook 2017. Armaments, Disarmament and International Security, Estocolmo, SIPRI.

SPIKINS, P.; HITCHENS, G. y NEEDHAM, A. P. (2017): "Strangers in a strange land?: Intimate sociality and emergent creativity in Middle Palaeolithic Europe", en Warren, G. y Finlayson, B. (eds.), The diversity of Hunter-gatherer pasts, Oxford, Oxbow, 1-17. SPIKINS, P. A.; RUTHERFORD, H. E. y NEEDHAM, A. P. (2010): "From Homininity to Humanity: Compassion from the Earliest Archaics to Modern Humans", Time and Mind, 3, 303-325.

STRINGER, C. y GAMBLE, C. (1996): En busca de los neandertales: la solución al rompecabezas de los orígenes humanos, Barcelona, Crítica.

TANCREDIBARONE, L.(2014): "Somosunamezcladeretalesdetodosnuestrosantepasados". Diario El País, https://elpais.com/elpais/2014/11/18/ciencia/1416305106_266934. html. [Consulta: 10-12-2017].

URRUTIA, P.; VILLELLAS, M. y VILLELLAS, A. (2016): The role of the eu and other third parties in promoting the gender, peace and security agenda in mediation and dialogue processes, Barcelona, Escola de Pau/Universitat Autònoma de Barcelona, http://www. woscap.eu/documents/131298403/131299900/WOSCAP+D4.9+Best+Practices+Rep ort+-+Gender+-+Final.pdf/d48d6b2a-c195-4d7d-8892-43ea72bcc635 [Consulta: 08- 
02-18].

VILA, A. y ESTEVEZ, J. (2010): "Naturaleza y Arqueología: La reproducción en sociedades cazadoras-recolectoras o la primera revolución reproductiva", Revista AtlánticaMediterránea de Prehistoria y Arqueología Social, 12, 9-23.

VILA, P. (2002): "Música e identidad. La capacidad interpeladora y narrativa de los sonidos", en Cuadernos de Nación. Músicas en transición, Bogotá, Ministerio de Cultura.

WELLER, J. M. (1949): "Paleontologic classification", Journal of Paleontology, 23, 680-690. WOLPOFF, M. H. (1999): Paleoanthropology, Nueva York, McGraw-Hill.

XUE, Y.; PRADO-MARTÍNEZ, J.; SUDMANT, P. H.; NARASIMHAN, V.; AYUB, Q.; SZPAK, M.; FRANDSEN, P.; CHEN, Y.; YNGVADÖTTIR, B.; COOPER, D. N.; DE MANUEL, M.; HERNÁNDEZ-RODRÍGUEZ, J.; LOBÓN, I.; SIEGISMUND, H. R.; PAGANI, L.; QUAIL, M. A.; HVILSOM, C.; MUDAKIKWA, A.; EICHLER, E. E.; CRANFIELD, M. R.; MARQUÉS-BONET, T.; TYLER-SMITH, C. y SCALLY, A. (2015): "Mountain gorilla genomes reveal the impact of long-term population decline and inbreeding", Science, $348,242-245$. 